contamination of the equipment at three or six months-five of the compressor tubing (four with obvious condensation), 17 of the nebuliser reservoirs (eight of which had residual fluid), and 13 of the (17) syringes. Most patients washed their nebulisers and attempted to dry them, but three patients dried their equipment by blowing air through the nebuliser via their compressor and none of these had contamination. The bacterial isolates were all environmental organisms of low pathogenicity-mainly oxidase positive and oxidase negative Gram negative rods, diphtheroids, and Staphylococcus epidermidis. Although these represent a potential source of infection, none of our patients developed infection with these organisms during the six months.

We therefore now recommend that, as well as regular washing of nebulisers, an essential part of cleaning is to dry the equipment thoroughly by blowing air through the tubing and nebuliser with the air compressor. As individual nebules are now commonly available the use of syringes to draw up nebuliser solution is rapidly declining and we no longer recommend their use.

C M B HIGGS

PATRICIA JONES

A R TANSER

Chest Unit,

Royal United Hospital,

Bath BA1 3NG

SIR,-We agree with Ms Kate L Barnes and colleagues ( 3 October, p 812) that bacterial contamination of home nebulisers may be a potential source of pathogens. Home nebulisers should be washed after use, then dried, and stored dry. The nebuliser should not be stored in a dilute solution of disinfectant, as recommended, since this could prove to be a further source of contamination.

MaEve G L Keaney L A GANGUL

Hope Hospital,

Salford M6 8HD

\section{The blood transfusion service and the National Health Service}

SIR,-Dr J R Y Ross (3 October, p 850) suggests that the Scottish Blood Transfusion Service may cope better because it receives more than twice as much money per head of population as its counterpart in England. As director of one of the Scottish transfusion centres I suggest that this figure needs further examination as there are several reasons why the two sets of expenditure figures quoted are not directly comparable.

Firstly, the figures for Scotland include the full cost of the Protein Fractionation Centre, which produces virtually all the plasma fractions used in Scotland (and Northern Ireland). I suspect that the English figures do not include the full costs of the Blood Products Laboratory at Elstree. This difference would be appreciable since the Protein Fractionation Centre represents around $20 \%$ of the expenditure of the Scottish transfusion service.

Secondly, there are several important differences in the activities of the Scottish and English services. For example, for about half the Scottish population the regional transfusion centres provide not only blood collection and processing but also the full range of routine and emergency hospital blood banking services. At my own centre, for example, we do all the hospital blood banking for the whole of Edinburgh except one hospital; this includes compatibility testing of nearly 30000 patient samples per year and accounts for an appreciable proportion of our total expenditure. Other services provided by Scottish regional transfusion centres include tissue typing, the regional cell separator unit, and immunology services. The Scottish centres also produce reagents for blood typing, which have an estimated commercial value of over £lm a year.

Finally, the simple arithmetic of blood collection may account for a fair part of the cost differential. The blood collection rate in Scotland in 1985 was about 58000 units per million population per year compared with an average in England of about 45000 . Whether or not one accepts that the official handling charge of $£ 23$ per unit bears any relation to the actual cost of collecting and processing a uni of blood, a higher collection rate will inevitably lead to a higher per caput cost for the service concerned.

We have now entered a period when most of Britain's transfusion centres are under great pressure to maintain adequate levels of blood collection. The many new problems we face will almost inevitably lead to increases in the cost of providing an adequate transfusion service. My plea is that we do not cause extra difficulties for our national effort to provide a safe and cost effective transfusion service by using incomplete financial information

\section{B L McClelland}

Royal Infirmary,

Edinburgh EH3 9HB

\section{Potassium citrate: soothing but not harmless?}

SIR,-I learnt the Lesson of the Week (17 October, p 993) the hard and stupid way-in other words, by personal experience.

A few days after unexceptionable transurethral prostatic resection painful micturition. convinced me that I had an infection. While awaiting the culture result I persuaded my sympathetic house surgeon to prescribe potassium citrate mixture on the grounds that it could do no harm, and, anyway, when I had been a houseman in the same hospital 44 years previously it was about the only relevan medication available. The mixture arrived at the bedside, and I proceeded surreptitiously to consume it, unmonitored, in at least double the prescribed dosage. After 48 hours to the urinary discomfort were added the most appalling nausea, peculiar muscle weakness, and spontaneous vomiting, all of which terrified me and mystified my carers until electrolyte measurement revealed hyperkalaemia $(6.7 \mathrm{mmol} / \mathrm{l})$ and taught them to beware of doctors as patients. The culture, incidentally, was sterile. My general and renal health has been excellent, before and since.

South Mimms,

A L FAWDRY Hertfordshire EN6 3PS

\section{Soviet health care at first hand}

SIR, - I recently had first hand experience of being admitted to hospital in Samarkand, Russian Central Asia. As suggested by Michael Ryan in his article on funding for the Soviet health service (12 September, p 652), the resources of the hospital were minimal and the facilities and equipment very basic indeed.

While touring the region with my husband I was taken ill during the night with frequent and violent bouts of sickness and diarrhoea beyond the normal expected hazard of foreign travel. As this particular attack was so severe my husband called on the hotel staff for help, our own preventive medication brought with us from the UK proving ineffectual.
This account is not intended as a criticism of the $\underline{\underline{T}}$ treatment I received. It was prompt, thorough, $>$ and effective and I suffered no recurrence. The $\mathbb{\&}$ hotel staff quickly summoned their paramedical $C$ team of three, who through an interpreter inquired of my symptoms and then advised my dispatch to the nearest hospital for treatment. At this point I learnt that another of our party had suffered similar symptoms and was at that moment on his way to hospital. As soon as the ambulance returned I was given a towel in case I was sick on the journey (which I was) and driven the short distance to the nearest hospital.

The entrance to the hospital was kept permanently barred by iron doors and immediately closed behind the ambulance. When visiting later my husband told me that he was admitted only after scrutiny through an iron grille as if he were visiting a prisoner. He also glanced through the windows of the various single storey buildings which made up the compound and noticed beds in the various wards that were so close there was no room to walk between. The "ward" I was admitted to proved to be an $\mathrm{L}$ shaped room about $5 \mathrm{~m}$ by $4 \mathrm{~m}$ containing five bedsteads with springs like hammocks. In one of these beds was the other man from my hotel, whom I came to know rather well since his bed was next to mine with two chairs draped with a blanket as a screen. We shared a toilet which adjoined the room and which indeed had to be passed through to enter. This toilet had a permanently running defective cistern which ó would not flush and no seat. However, there was a $O$ bath, from the tap of which a basin could be filled and poured into the toilet pan. The bath itself had $A$ obviously not been used for a long time because the $Z$ waste pipe was not connected. As a final indignity this toilet had no door and was open to the street outside. The room itself had two large windows, one of which had an ill fitting fly screen. Neither had blinds or curtaining and passers by could (and did) peer in at what was taking place within. There were three light switches, but only a single fluorescent tube worked, and there were no power points at all. The bedding was of doubtful cleanliness, cracked linoleum was on the floor, decoration was long overdue, and many flies were a constant irritation.

Both of us patients received similar treatment in quick succession. The absence of anyone who could speak English (or French or German tried in turn) made communication difficult, but after we had made our symptoms known by signs the doctor and three nurses swung into action. I must again emphasise that I do not complain at the treatment received, which was effective, if crude. I was given a pail of water and an enamel saucepan and by signs instructed to drink as much as I could as quickly as I could to induce vomiting. When this was only partially successful I was advised to put two fingers down my throat to complete the process. Then I was given an enema with warm $N$ water to complete the process of clearing out and a blood sample was taken. Finally I was given three $\frac{D}{0}$ jam jars (without lids) and asked to provide appropriate specimens for analysis. This I did with $N$ some difficulty in the toilet with no door. I was N then connected to a glucose and water drip through a needle in my arm (seven attempts to find a vein and no disposable needles). Altogether I received two pints.

I was kept in the hospital for about 24 hours, ? during which time $I$ had one wash in a none too clean basin (through the intervention of my husband with the aid of an acquired phrase book). Some biscuits, salty water, and yoghourt were provided as sustenance. Neither of us could face the two hard boiled eggs that were also supplied. Both my fellow patient and I had a restful night and 8 as far as we know were not disturbed by any visit 
until the morning. Just before discharge a smartly attired young doctor entered our room with an entourage of students. He was somewhat taken aback to find two foreigners with whom he could not converse and left after a short while. I was given a pill and left the hospital in a car provided by Intourist. Thus ended my brush with the Soviet health service. My fellow patient received some aftercare as he vomited blood during one of his bouts of sickness and an ulcer was, I believe, suspected. His request to travel by air instead of by coach as scheduled was acceded to and he was afforded every facility and help until we reached our next destination.

Brighton BN1 8WR

DOROTHY J TROTT

\section{Points}

\section{Financial incentives of subregional RAWP}

Dr L J OpIT (Health Services Research Unit, University of Kent, Canterbury CT2 7NF) writes: Messrs Gwyn Bevan and John Brazier (3 October, p 836) make clear the absurdity of attempting to operate two separate criteria of fairness in dealing with the financing of district health authorities with large cross boundary flows. The logic implies strongly that new methods of capitation funding or cross boundary charging will not deal adequately with the problem of heavy use of services by district residents. Even if such methods guarantee more funding for inner London districts this money will be removed "unfairly" from other districts that are more self contained in their management of resident populations. One solution to the problem could be to redefine district health authorities' boundaries in such a way that they recognise the reality of this interdistrict traffic. This could even mean the development of London health authority(s) whose administrative boundaries would cause much of the cross boundary traffic to disappear and thus allow a return of funding per head as the model for redistribution.

\section{Undescended testes in low birthweight infants}

Mr H H Nixon (Hospital for Sick Children, Great Ormond Street, London WCIN 3JH) writes: Drs R Morley and $A$ Lucas comment on the rising incidence of undescended testes (26 September, p 753). Perhaps one reason is implicit in their definition of an undescended testis as "one that could not be brought down to the bottom of the scrotum by manipulation." The late Sir Denis Browne taught that any testis that could be manipulated into the scrotum-whether or not it reached the bottom-was a normal variant ("high" and "low" retractile testes). ${ }^{1} \mathrm{~A}$ follow up in 1977 of patients so diagnosed between 1953 and 1960 by Sir David Innes Williams or myself showed that in all cases traced the testes were in the scrotum. ${ }^{2}$ Also it has become common to measure descent by the distance in millimetres below the pubic tubercle. This seems to me less important than the relation of the organ to the scrotum, as it is sometimes possible to coax a testis quite a distance down alongside the scrotum without entering it.

Browne D. Treatment of undescended testes. Proc $R$ Soc Med 1949;42:643.

2 Puri P, Nixon HH. Bilateral testes - subsequent effects on fertility. $\mathcal{F}$ Pediatr Surg 1977;12:563-5.

\section{Radiological diagnosis of deep vein thrombosis}

Dr I M Al-Khawaja (Oldchurch Hospital, Romford RM7 OBE) writes: Particulate radionuclide venography has many advantages for thrombophlebitis detection (Professor Graham Whitehouse, 3 October, p 801). Phlebitis and pulmonary embolism may coexist in half of all patients. Thus it is useful to combine perfusion lung scanning and radionuclide venography in one procedure. Instead of the routine antecubital injection for the lung scan the injection is made into a dorsal foot vein. Both legs should be njected simultaneously for comparison. Sequential mages of the tracer flow through the calf, thigh, and iliac regions are recorded. Normally, a single deep channel is visualised. ${ }^{1}$ The presence of obstruction, collateral circulation, or slow flow suggests venous thrombosis. The sequential images can be followed immediately by the routine perfusion lung scan images. Therefore, radionuclide venography separates the low risk non-phlebitic patient from the high risk group with venous disease. It also differentiates myositis from phlebitis, a distinction not usually possible with labelled fibrinogen. ${ }^{2}$ Radionuclide venography yields $95 \%$ correlation with Doppler and contrast venography for detecting disease below the thighs. It is also more accurate than these procedures in non-obstructive phlebitis.

1 McDonald GB, Hamilton, GW Barnes RW, et al. Radionuclide venography. I Nucl Med 1973;14:528-30.

2. Webber MM, Pollak EW, Victrey W, et al. Thrombosis detection by radionuclide particle (MAA) entrapment: correlation with fibrinogen uptake and venography. Radiology 1974;111:64550.

\section{AIDS and tuberculosis}

Dr Ivan A D'Cruz (VA Medical Center, Augusta, GA 30910, USA) writes: Dr K P Goldman (29 August p 511) called attention to the frequent incidence and varied forms of tuberculosis reported in patients with the acquired immune deficiency syndrome (AIDS) The latter included involvement of lungs, lymph nodes, bone marrow, genitourinary tract, liver, peritoneum, meninges, and brain. To this list may be added tuberculous pericarditis, which in our case caused a large effusion.

Cardiac disease in AIDS has been well documented $^{24}$ but is usually overshadowed by pulmonary and other manifestations. These few reports of myocardial and pericardial disease tend to be submerged into obscurity by the flood of reports on all other aspects of AIDS. However, if sought by echocardiography cardiac manifestations may be detected more often than is now the case and when present prove an important factor in prognosis.

1 D'Cruz IA, Sengupta EE, Abrahams C, Reddy HK, Turlapat RV. Cardiac involvement, including tuberculous pericardia effusion complicating acquired immune deficiency syndrome. Am Heart f 1986;112:1 100.

2 Fink L, Reichek N, Sutton MG. Cardiac abnormalities in acquired immune deficiency syndrome. Am 7 Cardiol 1984;59. 1161.

3 Cammorosano C, Lewis F. Cardiac lesions in acquired immun deficiency syndrome. 7 Am Coll Cardiol 1985;5:703.

Cohen IS, Anderson DW, Virmoni R, et al. Congestive cardiomyopathy in association with the acquired immunodeficiency syndrome. N Engl F Med 1986;315:628.

\section{Breast cancer}

Mrs Patricia MoORe (Sevenoaks, Kent TN13 3XH) writes: Like Dr Angela Prior (10 October, p 920), too have breast cancer and very positive ideas about what should be done with my body. It is now 10 months since I turned up at the surgery with a tumou $3.5 \times 2.5 \mathrm{~cm}$ on the left breast. It had burst and was discharging smelly colourless fluid. I had let the lump develop until it burst for no other reason than a determination not to go through the cancer "sausage machine." For many years I had watched with dismay the treatment meted out to friends and close colleagues. In every case there was a fatal outcome within a year or two. I said straight away that I would not consider surgery or radiotherapy. Tamoxifen 10 $\mathrm{mg}$ twice daily is the only treatment I have had. A year ago I looked haggard and had a general malaise which made me feel much more than my 64 years. Since the discharge started (it has sometimes been quite unpleasant) my health has improved steadily. I now look and feel fit and have regained my old fighting style. During the past few weeks the tumour has granulated and shrunk, the breast has taken up its proper contours, the mass around the tumour and the node in the axilla have gone, and the discharge has all but stopped. I have been fortunate in that neither my general practitioner nor the consultant, a radiotherapist, has tried to make me agree to any other treatment. This treatment would probably not be adequate for all patients with breast cancer, but it is neither destructive nor irreversible and could be tried first.

\section{Growing up with chronic renal failure}

Dr S SINGH (Child and Family Health Unit, South Western Hospital, London SW9 9NU) writes: Dr M H Winterborn rightly emphasises the multidisciplinary approach to the care of children in the community (10 October, p 870), but he fails to mention either the school doctor or the school nurse. Not only does the school health service assess the child's educational needs (Education Act 1981) but the medical officer can contribute to the continuing support of the child and family as well as tackle some of the practical problems (enuresis) which can take on magnified proportions in a school environment. Since mainstream schooling can only enhance a uraemic child's educational and social development this aspect of care shodld not be neglected.

\section{Alcohol and accidents}

Miss M A Hocking (Accident and Emergency Department, Lewisham Hospital, London SE136LH) writes: In your report of the Central Committee for Hospital Medical Services' discussion on alcohol consumption (3 October, p 866) you quote $\mathrm{Dr} J \mathrm{M}$ Cundy as saying that among the 450 people injured by assaults and attending Lewisham Hospital in the past three years, alcohol had been found to be the provoking factor in $60 \%$ of them. I do not know exactly what Dr Cundy said but the true figures are as follows. Over three months 425 patients attended the accident and emergency department after an assault. In 348 cases the casualty officer had recorded whether or not alcohol was a factor and it appeared to have been implicated in at least half of these patients.

Intellectual performance of children after whooping cough

Mr R W PORTER (Doncaster Royal Infirmary, Doncaster DN2 5LT) writes: The Swansea Research Unit shows an interesting association between the serious complications of whooping cough and the subsequent intellectual performance of children (24 October, $p$ 1044). It concludes that this may be related to apnoea, fits, or other factors. Our studies of the vertebral canal have shown some evidence for a relation between the development of the neuroosseous and the immune systems, populations with small vertebral canals also having some impairment of the immune and central nervous systems. ${ }^{1}$ Only a prospective study would have shown whether the Swansea children had both intellectual and immune impairment predating their whooping cough infection. It would then not be surprising that they had previously suffered significantly more recurrent bronchitis and ear infections than the controls.

1 Porter RW, Drinkall JN, Porter DE, Thorp L. The vertebral canal-part 2: Health and academic status: a clinical study. Spine (in press).

\section{Correction}

\section{The fertility debate and the media}

We regret that an error occurred in this letter by Professor Ian Craft and others (31 October, p 1134). At the end of the fifth paragraph it was stated that the first UK twins and triplets were approaching 4 and 3 years of age respectively. This should have read 6 and 4 years respectively. 